\title{
TGF $\beta$-induced switch from adipogenic to osteogenic differentiation of human mesenchymal stem cells: identification of drug targets for prevention of fat cell differentiation
}

Everardus J. van Zoelen ${ }^{1,2^{*}}$, Isabel Duarte ${ }^{1,2,3}$, José M. Hendriks ${ }^{1,2,4}$ and Sebastian P. van der Woning ${ }^{1,2,5}$

\begin{abstract}
Background: Patients suffering from osteoporosis show an increased number of adipocytes in their bone marrow, concomitant with a reduction in the pool of human mesenchymal stem cells (hMSCs) that are able to differentiate into osteoblasts, thus leading to suppressed osteogenesis.

Methods: In order to be able to interfere with this process, we have investigated in-vitro culture conditions whereby adipogenic differentiation of hMSCs is impaired and osteogenic differentiation is promoted. By means of gene expression microarray analysis, we have investigated genes which are potential targets for prevention of fat cell differentiation.

Results: Our data show that BMP2 promotes both adipogenic and osteogenic differentiation of hMSCs, while transforming growth factor beta (TGF $\beta$ ) inhibits differentiation into both lineages. However, when cells are cultured under adipogenic differentiation conditions, which contain CAMP-enhancing agents such as IBMX of PGE2, TGF $\beta$ promotes osteogenic differentiation, while at the same time inhibiting adipogenic differentiation. Gene expression and immunoblot analysis indicated that IBMX-induced suppression of HDAC5 levels plays an important role in the inhibitory effect of TGF $\beta$ on osteogenic differentiation. By means of gene expression microarray analysis, we have investigated genes which are downregulated by TGF $\beta$ under adipogenic differentiation conditions and may therefore be potential targets for prevention of fat cell differentiation. We thus identified nine genes for which FDA-approved drugs are available. Our results show that drugs directed against the nuclear hormone receptor PPARG, the metalloproteinase ADAMTS5, and the aldo-keto reductase AKR1B10 inhibit adipogenic differentiation in a dose-dependent manner, although in contrast to TGF $\beta$ they do not appear to promote osteogenic differentiation.
\end{abstract}

Conclusions: The approach chosen in this study has resulted in the identification of new targets for inhibition of fat cell differentiation, which may not only be relevant for prevention of osteoporosis, but also of obesity.

Keywords: Mesenchymal stem cell, Adipogenesis, Osteogenesis, Osteoporosis, Bone marrow, Histone deacetylase, Metalloproteinase, Aldo-keto reductase

\footnotetext{
* Correspondence: jovazo@wxs.nl

'Department of Cell and Applied Biology, Faculty of Science, Radboud

University Nijmegen, PO Box 9010, 6500 GL Nijmegen, The Netherlands

${ }^{2}$ Present Address: Department of Cell and Applied Biology, Radboud

University Nijmegen, Heyendaalseweg 135, 6525 AJ Nijmegen, The

Netherlands

Full list of author information is available at the end of the article
} 


\section{Background}

Human mesenchymal stem cells (hMSCs) from bone marrow have the ability to differentiate into cells from multiple lineages, including osteoblasts and adipocytes. The commitment of hMSCs towards either the osteogenic or adipogenic lineage depends on the local availability of growth factors and hormones, which are able to activate lineagespecific transcriptional regulators [1]. Patients suffering from osteoporosis show an increased number of adipocytes in their bone marrow, concomitant with a reduction in the pool of hMSCs that are able to differentiate into osteoblasts, thus leading to suppressed osteogenesis [2, 3]. It is still unclear to what extent this age-related increase in differentiation of hMSCs towards adipocytes results from intrinsic changes in the stem cells or from alterations in the microenvironment of the bone marrow [1, 4]. These observations have recently stirred increasing interest in anabolic therapies for osteoporosis, whereby osteogenic differentiation of hMSCs is stimulated by preventing adipogenic differentiation $[5,6]$.

Most information about the signaling pathways that are required for osteogenic and adipogenic differentiation of hMSCs has come from in-vitro studies, whereby cells are treated with specific combinations of growth factors and hormones [7]. Differentiation into both lineages requires treatment of monolayer cells with dexamethasone (DEX) and is enhanced by the presence of bone morphogenetic proteins (BMPs). Osteogenic differentiation is obtained by the additional presence of ascorbate and $\beta$-glycerophosphate, whereas adipogenic differentiation requires treatment with insulin, 3-isobutyl-1-methylxanthine (IBMX), and the PPARG activator rosiglitazone. Our previous data have indicated that under these experimental conditions at least $75 \%$ of the hMSCs differentiate into either osteoblasts or adipocytes [7].

Activation of the RUNX2 nuclear transcription factor appears to be essential for the osteogenic pathway of hMSCs, while the adipogenic pathway requires the transcriptional activity of the PPARG nuclear hormone receptor [1]. Evidence has been presented that transcriptional regulators promoting differentiation into one of these lineages actively suppress differentiation into the other lineage [8]. It has therefore been postulated that a reciprocal relationship exists between the osteogenic and adipogenic pathways, implying that impaired adipogenic differentiation of hMSCs may result in enhanced osteogenic differentiation [3].

Multiple regulators are known that affect the choice between the osteogenic and adipogenic lineage. Most notably, activation of the $\mathrm{WNT} / \beta$-catenin pathway promotes osteogenic differentiation and inhibits adipogenic differentiation of hMSCs [9]. BMP enhances the outgrowth of both osteoblasts and adipocytes, while the related cytokine transforming growth factor beta (TGF $\beta$ ) inhibits both osteogenic and adipogenic differentiation, at least when tested under these in-vitro conditions [10, 11]. Moreover, Kim et al. [12] have shown that cAMP-activated protein kinases regulate the differentiation choice of hMSCs between osteogenesis and adipogenesis.

In order to find drugs affecting the choice between osteogenic and adipogenic differentiation of hMSCs, we have optimized the adipogenic culture conditions in such a way that, within the same culture, a fraction of the cells differentiates into osteoblasts and another fraction into adipocytes. Our results show that addition of TGF $\beta$ to these cultures fully blocks adipogenic differentiation but, surprisingly, enhances osteogenic differentiation. Analysis of the individual components in the culture medium showed that the presence of the phosphodiesterase inhibitor IBMX, which stabilizes cAMP levels in the cell, converted TGF $\beta$ from an inhibitor to an enhancer of osteogenic differentiation.

Based on these observations we have set up a gene expression microarray experiment to identity genes that under these optimized adipogenic culture conditions are downregulated by TGF $\beta$. The genes identified in this way seem to play an important role in adipogenesis, since inhibitors of the corresponding proteins were found to be able to block adipogenic differentiation of hMSCs. Some of these inhibitors have already received FDA approval for the treatment of various diseases, and may therefore be good candidates for therapeutic drug repurposing in order to treat patients suffering from such diseases as obesity and osteoporosis.

\section{Methods}

\section{Culture and differentiation of hMSCs}

hMSCs harvested from normal human bone marrow were purchased from Lonza (Walkersville, MD, USA) at passage 2. Cells were expanded for no more than five passages in "mesenchymal stem cell growth medium" (MSCGM; Lonza) at $37{ }^{\circ} \mathrm{C}$ in a humidified atmosphere containing $7.5 \% \mathrm{CO}_{2}$. Studies were performed with hMSCs from three different donors, encoded 5F0138, 6F4085, and 7F3458.

For differentiation experiments, $4.0 \times 10^{4}$ cells per $\mathrm{cm}^{2}$ were seeded in high-glucose-containing Dulbecco's modified Eagle's medium (DMEM) supplemented with $10 \%$ fetal bovine serum (a selected lot from Lonza), 100 $\mathrm{U} / \mathrm{ml}$ penicillin, and $100 \mu \mathrm{g} / \mathrm{ml}$ streptomycin. This medium will be further referred to as "proliferation medium" (PM). The next day, cells were switched to either osteogenic or adipogenic differentiation medium. Cells treated with PM were used as negative controls. Osteogenic differentiation medium (ODM) was composed of PM supplemented with $10^{-7}$ M DEX, $0.2 \mathrm{mM}$ ascorbate, and $10 \mathrm{mM} \beta$-glycerophosphate. Adipogenic differentiation medium (ADM) was composed of PM 
supplemented with $10^{-6} \mathrm{M}$ DEX, $10 \mu \mathrm{g} / \mathrm{ml}$ insulin (R\&D Systems, Minneapolis, MN, USA), $10^{-7} \mathrm{M}$ rosiglitazone (Sigma-Aldrich, St. Louis, MO, USA), and $500 \mu \mathrm{M}$ IBMX (Sigma-Aldrich). Unless indicated otherwise, recombinant human TGF $\beta 1$ and BMP2 (both from R\&D Systems) were used at concentrations of $2 \mathrm{ng} / \mathrm{ml}$ and $125 \mathrm{ng} / \mathrm{ml}$, respectively. Prostaglandin E2 (PGE2), Batimastat, and Zopolrestat (Sigma-Aldrich) were used at the indicated concentrations. Media were refreshed every 3-4 days.

\section{Alkaline phosphatase assays}

To quantify alkaline phosphatase (ALP) enzymatic activity as a measure of osteogenic differentiation, hMSCs were seeded in 96-well tissue culture plates as already described, after which cells were differentiated for 7 days in osteogenic differentiation medium. ALP enzymatic activity was quantified by measuring the formation of $p$-nitrophenol from $p$-nitrophenyl phosphate (PNPP; SigmaAldrich), as described previously [13]. ALP enzymatic activity was corrected for differences in cell number, as determined by a Neutral Red assay. Cells were incubated with Neutral Red dye diluted in PBS for 1 hour at $37^{\circ} \mathrm{C}$. After washing with PBS, the dye was extracted from the cells using $0.05 \mathrm{M} \mathrm{NaH}_{2} \mathrm{PO}_{4}$ in $50 \% \mathrm{EtOH}$, after which the absorbance was measured at $540 \mathrm{~nm}$.

For histochemical analysis of ALP activity, cells were seeded in 48-well tissue culture plates and differentiated for 7 days in osteogenic differentiation medium. Subsequently, cells were fixed in $3.7 \%$ formaldehyde/PBS for $10 \mathrm{~min}$ at $22{ }^{\circ} \mathrm{C}$. After washing with PBS, cells were incubated for 1 hour at $37{ }^{\circ} \mathrm{C}$ in a mixture of $0.1 \mathrm{mg} / \mathrm{ml}$ naphtol ASMX phosphate (Sigma-Aldrich), $0.5 \% \mathrm{~N}, \mathrm{~N}$-dimethylformamide, $2 \mathrm{mM} \mathrm{MgCl}_{2}$, and $0.6 \mathrm{mg} / \mathrm{ml}$ Fast Blue BB salt (Sigma-Aldrich) in $0.1 \mathrm{M}$ Tris- $\mathrm{HCl}, \mathrm{pH} 8.5$.

\section{Mineralization assay}

To measure calcium deposition in the extracellular matrix, hMSCs were seeded in 24-well tissue culture plates and cultured for 13 days under osteogenic or adipogenic differentiation conditions, as indicated. Cells were subsequently washed twice with PBS after which calcium was extracted from the extracellular matrix by treatment with $150 \mu \mathrm{l}$ of $0.5 \mathrm{M} \mathrm{HCl}$. Calcium concentrations were measured in a colorimetric assay using $o$ cresolphtalein complexone as a chromogenic agent, according to the protocol provided by the manufacturer (Sigma-Aldrich).

\section{Oil Red $\mathrm{O}$ staining and Triglyceride assay}

To quantify adipogenic differentiation, lipid droplets were stained in mature adipocytes obtained after treatment of hMSCs for 9 days in adipogenic differentiation medium. Cells were first washed twice with PBS, fixed for 30 min with $1 \%$ formaldehyde in PBS, and then washed once with water and twice with $60 \%$ isopropanol. Cells were then stained for 1 hour with $0.3 \%$ w/v Oil Red O (Sigma-Aldrich) in $60 \%$ isopropanol. Subsequently, cells were washed once with $60 \%$ isopropanol and twice with distilled water. For quantification of Oil Red O staining, samples were treated with $100 \%$ isopropanol and absorbance was measured at $530 \mathrm{~nm}$.

The amount of triglycerides stored in lipid droplets of mature adipocytes was quantified after treatment of hMSCs for 9 days in adipogenic differentiation medium. Cells in 96-well tissue culture plates were washed twice with PBS. Triglycerides were extracted from the lipid droplets by freezing the cells in $50 \mu \mathrm{l}$ of a buffer containing $25 \mathrm{mM}$ Tris- $\mathrm{HCl}(\mathrm{pH} 7.5)$ and $1 \mathrm{mM}$ EDTA, followed by addition of $40 \mu \mathrm{l}$ tert-butanol and $10 \mu \mathrm{l}$ methanol. Samples were heat-dried at $55{ }^{\circ} \mathrm{C}$, after which they were resuspended in Triglycerides LiquiColor mono reagents (HUMAN GmbH, Wiesbaden, Germany). Triglycerides were quantified by measuring the absorbance at $490 \mathrm{~nm}$.

\section{RNA isolation and real-time quantitative RT-PCR}

RNA was isolated as described by Piek et al. [13]. For cDNA synthesis, $1 \mu \mathrm{g}$ of total RNA was reverse transcribed using random hexamer primers and SUPERSCRIPT $^{\text {tox }}$ II reverse transcriptase (Invitrogen, Carlsbad, CA, USA). Subsequently, cDNA was amplified in a quantitative real-time PCR, performed using Power SYBR Green ${ }^{\bullet}$ PCR Mastermix (Applied Biosystems, Foster City, CA, USA) on an Applied Biosystems 7500 Real-time Fast PCR System. For each gene, PCR was carried out in duplicate and mean expression values were calculated relative to the mean expression level of the housekeeping gene RPS27A (ribosomal protein S27a). Human gene-specific PCR primers used included the following:

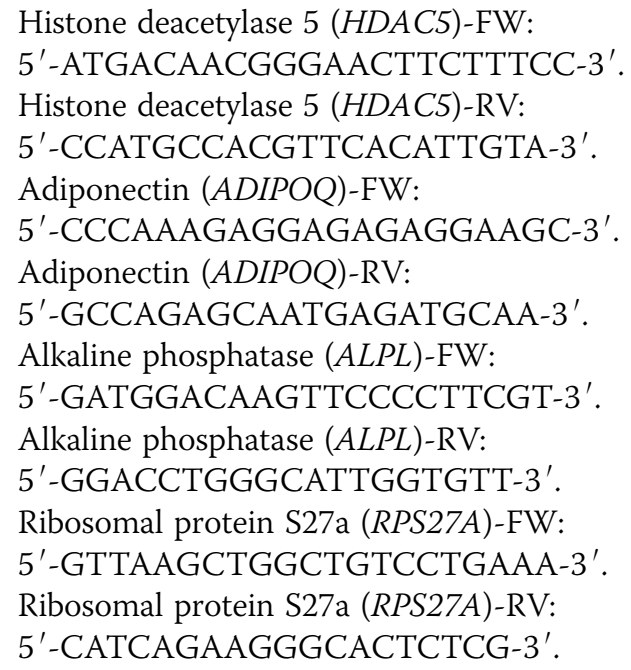

Histone deacetylase 5 (HDAC5)-FW:

5'-ATGACAACGGGAACTTCTTTCC-3'.

Histone deacetylase 5 (HDAC5)-RV:

5'-CCATGCCACGTTCACATTGTA-3'.

Adiponectin (ADIPOQ)-FW:

5'-CCCAAAGAGGAGAGAGGAAGC-3' .

Adiponectin (ADIPOQ)-RV:

5'-GCCAGAGCAATGAGATGCAA-3' .

Alkaline phosphatase (ALPL)-FW:

5'-GATGGACAAGTTCCCCTTCGT-3'.

Alkaline phosphatase (ALPL)-RV:

5'-GGACCTGGGCATTGGTGTT-3'.

Ribosomal protein S27a (RPS27A)-FW:

5'-GTTAAGCTGGCTGTCCTGAAA-3'.

Ribosomal protein S27a (RPS27A)-RV:

5'-CATCAGAAGGGCACTCTCG-3'. 


\section{Immunoblotting}

hMSCs were seeded at $4.0 \times 10^{4}$ cells per $\mathrm{cm}^{2}$ in six-well plates and cultured for 24 hours in the indicated differentiation media. Cells were then lysed in $250 \mu \mathrm{l}$ of RIPA lysis buffer per well. Then $5 \mu \mathrm{l}$ of reducing sample buffer was added to $25 \mu$ of lysate, heated to $95^{\circ} \mathrm{C}$, and subsequently loaded onto an $8 \%$ SDS-PAGE gel. HDAC5 was detected on blots using a goat polyclonal anti-HDAC5 antibody (G-18, 1/200 dilution) raised against the N-terminus of human HDAC5 (sc-5250; Santa Cruz Biotechnology, Dallas, TX, USA), followed by an HRP-labeled polyclonal secondary antibody. Antibodies against $\alpha$-tubulin (Sigma) served as a loading control.

\section{Gene expression microarray analysis}

To identify genes that are regulated during osteogenic and adipogenic differentiation of hMSCs, a total of 54 samples (each containing 800,000 cells/ $20 \mathrm{~cm}^{2}$ ) were seeded in PM and grown for 24 hours. Subsequently the medium was exchanged for differentiation medium, now consisting of PM with $10^{-6} \mathrm{M} \mathrm{DEX}, 10 \mu \mathrm{g} / \mathrm{ml}$ insulin, 10 ${ }^{-7} \mathrm{M}$ rosiglitazone, and $50 \mathrm{ng} / \mathrm{ml}$ BMP2 (B). In addition, either $5 \mathrm{ng} / \mathrm{ml}$ TGF $\beta$ (BT), or $250 \mu \mathrm{M}$ IBMX (BI), or $5 \mathrm{ng} / \mathrm{ml}$ TGF $\beta$ and $250 \mu \mathrm{M}$ IBMX (BTI) were added. Samples were incubated for either 0, 1, 2, 3, or 7 days. Experiments for each group and time point were carried out as three biological replicates, while the untreated control group (time 0) consisted of six samples. RNA was isolated as already described, and hybridized onto Affymetrix HGU 133 plus 2.0 microarrays according to existing protocols [13].

Microarray data were analyzed with the $\mathrm{R}$ language for statistical computing using appropriate Bioconductor packages (http://bioconductor.org/) for reading, normalizing, and statistically evaluating the data, followed by annotation of the gene sets and integration of parallel data sources. Briefly, the analysis started with a careful quality assessment of the dataset using the automatic $\mathrm{R}$ pipeline AffymetrixQC [14], which was customized and run locally. All 54 microarrays passed the quality control and were included in the analysis, consisting of robust microarray analysis (RMA) normalization [15], followed by statistical analysis to find differentially expressed genes using Linear Models for Microarray Data (LIMMA) [16], and subsequent functional annotation and enrichment analysis using the online resource Database for Annotation, Visualization and Integrated Discovery (DAVID) $[17,18]$. Finally, the list of differentially expressed genes for the contrasts of interest was crossed with the information from the DrugBank database [19] in order to derive the final list of candidate genes for experimental testing. All R scripts used for this analysis are available upon request. Current microarray data have been deposited in NCBI's Gene
Expression Omnibus [GEO:GSE84500] (https://www.ncbi. nlm.nih.gov/geo/query/acc.cgi?acc=GSE84500).

\section{Statistical analysis}

Student's $t$ test was used for statistical comparisons. Numeric data are represented as mean \pm standard deviation of triplicate experiments, unless stated otherwise.

\section{Results}

TGF $\beta$ induces hMSCs to switch from adipogenic to osteogenic differentiation

BMPs have been described as positive regulators of both osteogenesis and adipogenesis $[8,10]$. In order to study the effect of BMP2 on differentiation of hMSCs in more detail, we cultured these cells in either osteogenic differentiation medium or adipogenic differentiation medium in the absence and presence of BMP2. Figure 1a shows that addition of BMP2 has only a small stimulatory effect on adipogenic differentiation of hMSCs, as measured by the amount of the triglyceride production. On the other hand, BMP2 strongly enhanced osteogenic differentiation, as indicated by increased ALP activity (Fig. 1b).

The role of TGF $\beta$ in adipogenic and osteogenic differentiation of hMSCs is still unclear. Figure 1a also shows that adding TGF $\beta$ to adipogenic differentiation medium blocks adipogenic differentiation of hMSCs in a dose-dependent manner, both in the absence and additional presence of BMP2. Figure $1 \mathrm{~b}$ shows that addition of TGF $\beta$ to osteogenic differentiation medium results in a similar inhibition of osteogenic differentiation, both in agreement with previous data $[10,11]$. However, when hMSCs are treated with adipogenic differentiation medium (which contains a 10-fold higher concentration of DEX than osteogenic differentiation medium) in combination with BMP2, a fraction of the cells will differentiate into bone cells and a fraction into fat cells within the same well, as shown in Fig. 1c by histological staining. Addition of TGF $\beta$ under these conditions resulted is a dose-dependent increase in the number of ALP-positive bone cells, with a concomitant reduction in Oil Red O-positive fat cells. These data show that TGF $\beta$ blocks bone cell differentiation under osteogenic differentiation conditions, but enhances bone cell differentiation under adipogenic differentiation conditions. It can therefore be concluded that, under the experimental conditions used in Fig. 1c, TGF $\beta$ induces a switch from adipogenic to osteogenic differentiation.

\section{IBMX is a critical component in the TGF $\beta$-mediated switch in cell fate}

In order to investigate which component of the adipogenic differentiation medium allows osteogenic differentiation in the presence of TGF $\beta$, we added the adipogenic differentiation medium components insulin, IBMX, and rosiglitazone successively to hMSCs grown in osteogenic 

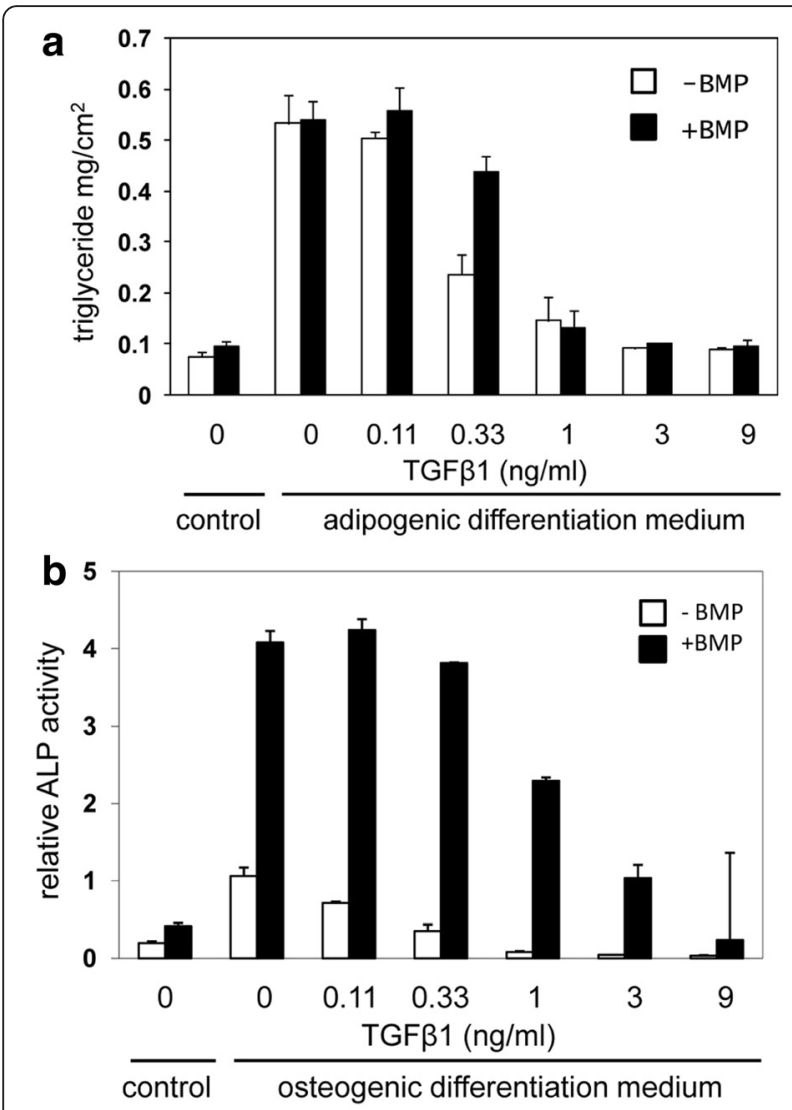

C

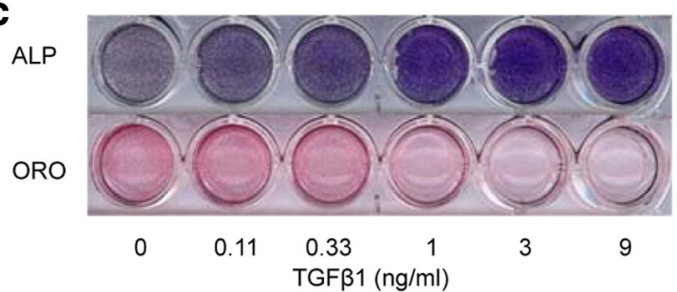

Fig. 1 Effect of TGF $\beta$ on adipogenic and osteogenic differentiation of hMSCs. a Triglyceride production by hMSCs, 9 days after incubation with adipogenic differentiation medium in the absence (white shading) and presence (black shading) of $125 \mathrm{ng} / \mathrm{ml} \mathrm{BMP2}$ and increasing concentrations of TGF $\beta 1$. The enhancing effect of BMP2 is not significant, while the inhibitory effect of TGF $\beta$ is significant $(p<0.01)$ above $1 \mathrm{ng} / \mathrm{ml}$. b Alkaline phosphatase (ALP) activity of hMSCs, 7 days after incubation with osteogenic differentiation medium in the absence (white shading) and presence (black shading) of $125 \mathrm{ng} / \mathrm{ml}$ BMP2 and increasing concentrations of TGF $\beta 1$. Enhancing effect of BMP2 is significant $(p<0.01)$ at all data points, while the inhibitory effect of TGF $\beta$ is significant $(p<0.01)$ above $1 \mathrm{ng} / \mathrm{ml}$. c TGF $\beta$-induced switch from adipogenic to osteogenic differentiation. ALP staining (after 7 days) and Oil Red $\mathrm{O}(\mathrm{ORO})$ staining (after 9 days) following incubation of hMSCs in adipogenic differentiation medium containing $125 \mathrm{ng} / \mathrm{ml} \mathrm{BMP} 2$ and the indicated concentrations of TGF $\beta 1$. BMP bone morphogenetic protein, TGF $\beta$ transforming growth factor beta

differentiation medium with BMP2 and TGF $\beta$. Figure 2a shows that the inhibition of osteogenic differentiation by TGF $\beta$ could not be prevented by insulin or rosiglitazone, but was largely overcome upon addition of IBMX. A parallel experiment showed that omission of IBMX from adipogenic differentiation medium was sufficient to prevent the TGF $\beta$-induced enhancement of osteogenic differentiation, while removal of insulin or rosiglitazone was without effect (Fig. 2b).

IBMX is a phosphodiesterase inhibitor, which prevents degradation of cAMP. In order to show that enhanced cAMP levels play a role in the TGF $\beta$-mediated switch in cell fate, we tested the effect of PGE2, a known activator of adenylate cyclase. Figure 2c shows that PGE2 is able to overcome TGF $\beta$-induced inhibition of osteogenic differentiation of hMSCs in a dose-dependent manner, to a similar extent as IBMX.

Osteogenic differentiation requires not only matrix maturation, as indicated by alkaline phosphatase expression, but also matrix mineralization, as indicated by calcium deposition. Figure $2 \mathrm{~d}$ shows that under osteogenic differentiation conditions BMP is required for calcium deposition by hMSCs, while both BMP and TGF $\beta$ are required under adipogenic differentiation. These data show TGF $\beta$ is able to induce fully differentiated, mineralized osteoblasts under adipogenic differentiation conditions.

\section{IBMX suppresses HDAC5 expression}

Previous studies [20] have shown that TGF $\beta$-mediated inhibition of osteogenic differentiation can be overcome by trichostatin A, an inhibitor of class I and II mammalian histone deacetylases (HDACs). We confirmed this observation upon incubating hMSCs in osteogenic differentiation medium with BMP2 and TGF $\beta$ (data not shown). Kang et al. [20] have presented evidence that HDAC4/5 can interact with TGF $\beta$-activated SMAD3, resulting in a complex that represses transcription of the bone marker gene osteocalcin (BGLAP). In human adipose-derived mesenchymal stem cells, trichostatin A impaired PPARG activity, at least under osteogenic differentiation conditions [21]. Still, the role of HDACs in adipogenesis is far from clear, since HDAC inhibitors may either enhance or inhibit adipogenic differentiation [22].

We have studied the expression of HDAC5 under conditions that TGF $\beta$ enhances osteogenic differentiation of hMSCs. Figure 3a shows that HDAC5 mRNA levels are slightly upregulated 24-48 hours after addition of osteogenic differentiation medium, particularly in the presence of BMP2 and TGF $\beta$ (OBT). A strong reduction in HDAC5 gene expression was observed when IBMX was added to the medium (OBTI), however, thus creating conditions under which adipogenic differentiation is prevented and osteogenic differentiation is promoted. Less reduction in HDAC5 mRNA levels was observed in adipogenic differentiation medium alone. We could not detect mRNA expression of HDAC4 in these cells.

Figure $3 \mathrm{~b}$ shows that HDAC5 levels are similarly regulated at the protein level. Western blot analysis revealed 

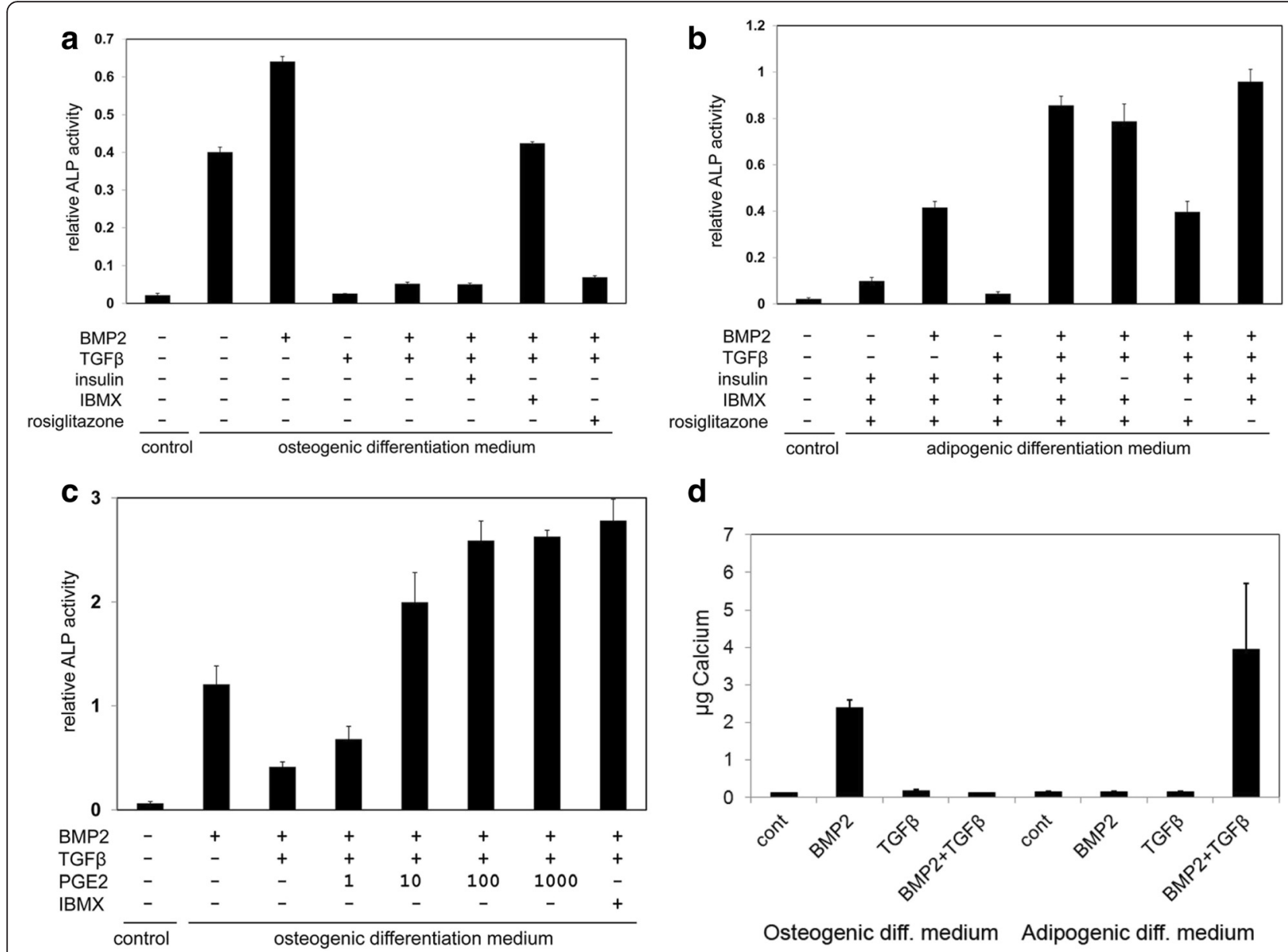

d

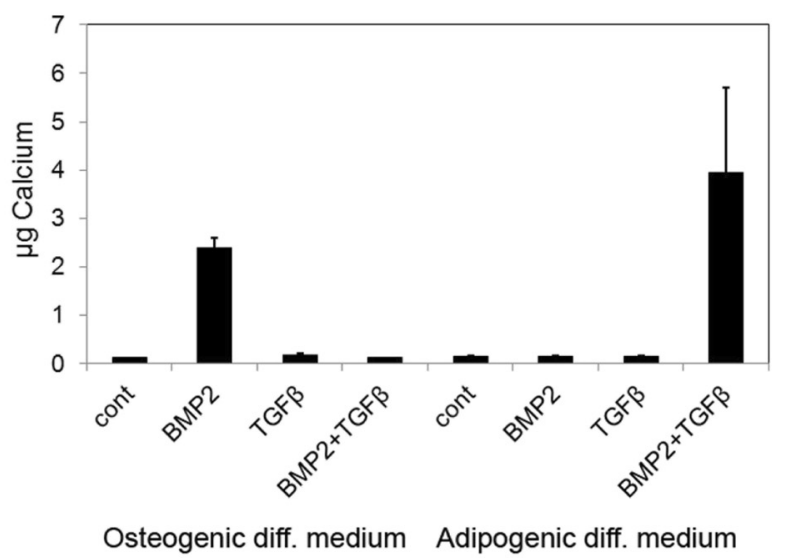

Fig. 2 CAMP regulators control TGF $\beta$-induced osteogenic differentiation of hMSCs. Osteogenic differentiation was measured by ALP activity and corrected for the level of Neutral Red uptake as a measure for the number of cells present in the well. a Osteogenic differentiation of hMSCs in osteogenic differentiation medium supplemented with or without $125 \mathrm{ng} / \mathrm{ml} \mathrm{BMP2,} 2 \mathrm{ng} / \mathrm{ml} \mathrm{TGF \beta 1,} 10 \mu \mathrm{g} / \mathrm{ml}$ insulin, $500 \mu \mathrm{M}$ IBMX, or $10^{-7} \mathrm{M}$ rosiglitazone. ALP activity is significantly higher $(p<0.001)$ in medium with BMP2 and TGF $\beta$ in the presence of IBMX than in the absence of IBMX. b Osteogenic differentiation of hMSCs in adipogenic differentiation medium supplemented with or without $125 \mathrm{ng} / \mathrm{ml}$ BMP2 and $2 \mathrm{ng} / \mathrm{ml}$ TGF $\beta 1$, and following omission of $10 \mu \mathrm{g} / \mathrm{ml}$ insulin, $500 \mu \mathrm{M}$ IBMX, or $10^{-7} \mathrm{M}$ rosiglitazone. ALP activity is significantly higher $(p<0.01)$ in medium with all supplements than in the absence of IBMX. c Effect of PGE2, added at the indicated nanomolar concentrations, on osteogenic differentiation of hMSCs in osteogenic differentiation medium. A comparison is made with the effects of BMP2 $(125 \mathrm{ng} / \mathrm{ml})$, TGF $(2 \mathrm{ng} / \mathrm{ml})$, and IBMX (500 $\mu$ M). Enhancement of ALP activity is significant $(p<0.05)$ at concentrations of $10 \mathrm{nM} \mathrm{PGE2}$ and above. $\mathbf{d}$ Effect of BMP2 $(125 \mathrm{ng} / \mathrm{ml})$ and TGF $(2 \mathrm{ng} / \mathrm{ml})$ on total $\mathrm{Ca}^{2+}$ deposition $(\mu \mathrm{g})$ in a six-well plate well $\left(10 \mathrm{~cm}^{2}\right)$ by hMSCs, cultured for 13 days in either osteogenic or adipogenic differentiation medium. $\mathrm{Ca}^{2+}$ deposition is significantly enhanced by BMP2 alone in osteogenic differentiation medium $(p<0.01)$ and by BMP2 + TGF $\beta$ in adipogenic differentiation medium $(p<0.05)$. ALP alkaline phosphatase, BMP bone morphogenetic protein, IBMX 3-isobutyl-1-methylxanthine, $P G E 2$ prostaglandin E2, TGF $\beta$ transforming growth factor beta

the highest expression level in hMSCs treated with osteogenic differentiation medium containing BMP2 and TGF $\beta$ (OBT), whereas almost no protein was detected in the additional presence of IBMX (OBTI). These data indicate that under conditions whereby TGF $\beta$ enhances osteogenic differentiation, no HDAC5 is available to prevent expression of bone specific genes.

\section{Altered gene expression during TGF $\beta$-mediated switch in cell fate}

The presented data show that, upon incubation of hMSCs in adipogenic differentiation medium containing BMP2 and IBMX, a fraction of the cells will differentiate into ALP-positive bone cells and a fraction into Oil Red Opositive fat cells. Subsequent addition of TGF $\beta$ reduces the number of fat cells and enhances the number of bone cells in a dose-dependent manner (see Fig. 1c). This observation implies that under these experimental conditions addition of TGF $\beta$ will stimulate the expression of osteoblast genes and reduce the expression of adipocyte genes. In order to identify genes involved in this lineage switch, we performed gene expression microarray analysis on hMSCs, treated for $1,2,3$, or 7 days with differentiation medium containing DEX, insulin, and rosiglitazone, using 


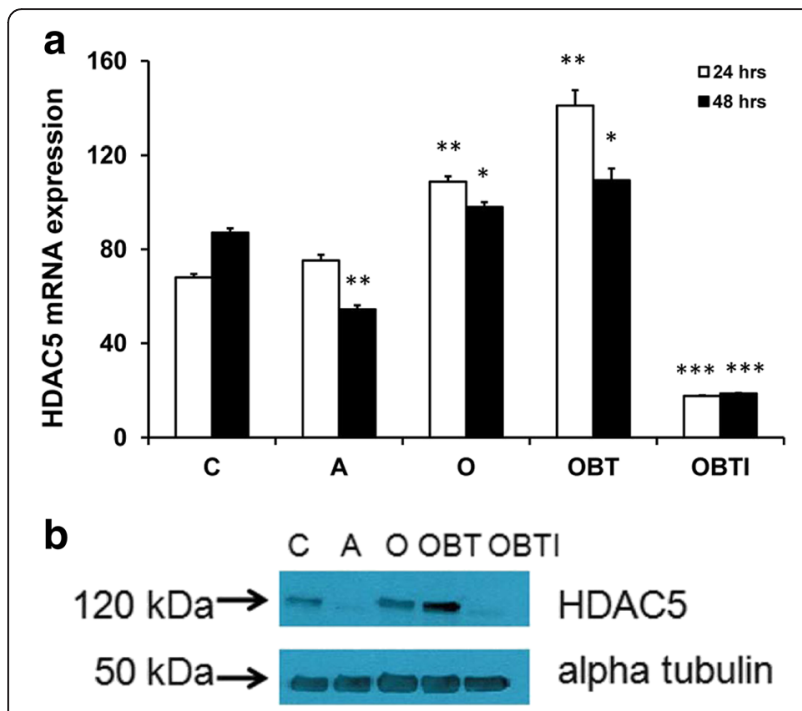

Fig. 3 IBMX controls HDAC5 expression levels in hMSCs. a HDAC5 mRNA levels, relative to that of the housekeeping gene RSP27A, of hMSCs incubated for 24 hours (white shading) or 48 hours (black shading) in proliferation medium $(C)$, adipogenic differentiation medium $(A)$, osteogenic differentiation medium $(O)$, osteogenic differentiation medium supplemented with $125 \mathrm{ng} / \mathrm{ml} \mathrm{BMP2}$ and $2 \mathrm{ng} /$ $\mathrm{ml}$ TGF $\beta(O B T)$, and osteogenic differentiation medium supplemented with $125 \mathrm{ng} / \mathrm{ml} \mathrm{BMP2,} 2 \mathrm{ng} / \mathrm{ml}$ TGF $\beta$, and $500 \mu \mathrm{M}$ IBMX (OBT). Data expressed as percentage of the expression levels at time zero. Results represent the mean and standard deviation of duplicate experiments. Indicated significance levels are relative to expression in control samples (C) at 24 or 48 hours, respectively. b Immunoblot for protein expression of HDAC5 in hMSCs, 5 days after incubation in the indicated media. Expression of a-tubulin was used as a loading control. ${ }^{*} p<0.05 ;{ }^{* *} p<0.01 ;{ }^{* * *} p<0.001$. HDAC histone deacetylase

as supplements BMP2 and combinations of IBMX and TGF $\beta$. Untreated cells at day 0 served as the control experiment. In order to verify the extent of differentiation of the cells used for the microarray experiments, we used real-time PCR to measure mRNA expression levels of the osteoblast-specific alkaline phosphatase $(A L P L)$ gene and of the adipocyte-specific adiponectin $(A D I P O Q)$ gene, a target gene of the adipogenic master gene PPARG. This analysis was carried out 7 days after incubation with BMP2 (B), BMP2 + TGF $\beta$ (BT), BMP2 + IBMX (BI), or $\mathrm{BMP} 2+\mathrm{TGF} \beta+\mathrm{IBMX}(\mathrm{BTI})$. Figure 4a shows that under these conditions IBMX, in combination with TGF $\beta$, enhanced ALPL expression. No inhibitory effect of TGF $\beta$ was observed on bone cell differentiation, in agreement with the data of Fig. 2b. ADIPOQ expression was strongly enhanced upon IBMX addition, but reduced again to very low levels in the additional presence of TGF $\beta$ (Fig. 4b). These data confirm that, at the gene expression level, TGF $\beta$ induces a switch from adipocytes to osteoblasts.

The data from the 54 microarray samples were normalized using RMA [15] followed by LIMMA [16] statistical analysis to identify differentially expressed genes and functional enrichment analysis using DAVID [17, 18]. From

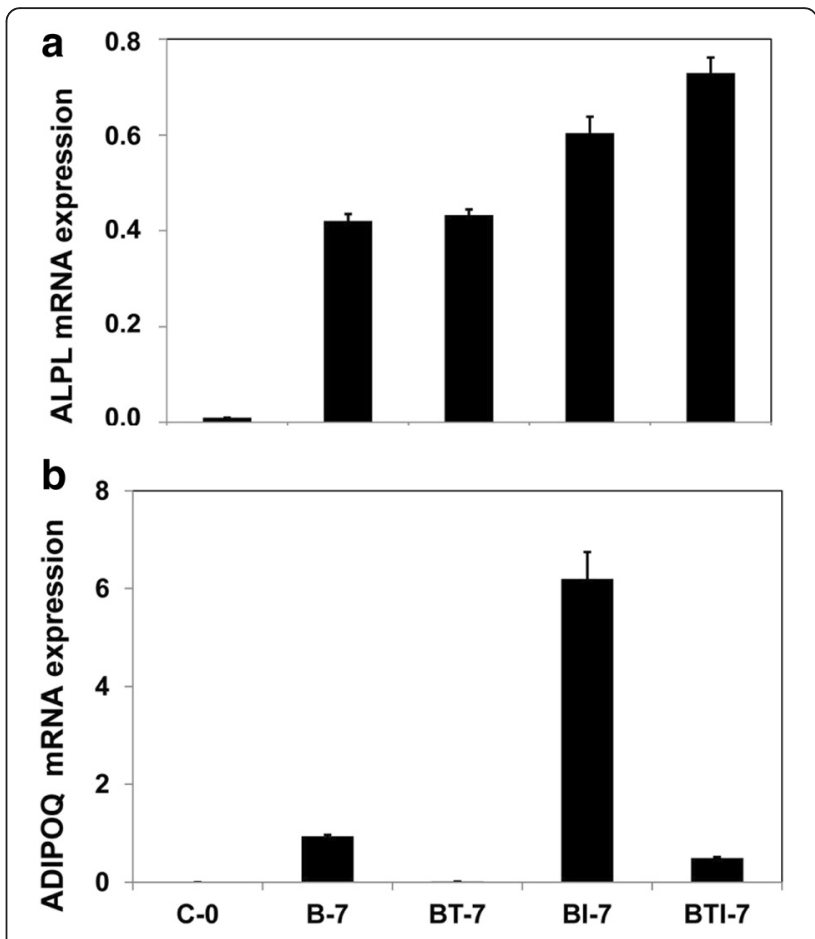

Fig. 4 Expression of osteogenic and adipogenic markers in hMSCs under conditions used for gene expression microarray analysis. Cells were incubated for 7 days in adipogenic differentiation medium containing $50 \mathrm{ng} / \mathrm{ml}$ BMP2 (B-7), $50 \mathrm{ng} / \mathrm{ml} \mathrm{BMP2}+5 \mathrm{ng} / \mathrm{ml}$ TGF $\beta$ $(B T-7), 50 \mathrm{ng} / \mathrm{ml} \mathrm{BMP2}+500 \mu \mathrm{M}$ IBMX (Bl-7), and $50 \mathrm{ng} / \mathrm{ml}$ BMP2 + $5 \mathrm{ng} / \mathrm{ml}$ TGF $\beta+500 \mu \mathrm{M}$ IBMX (BTI-7). Untreated cells at day zero (C-0) were used as a control. a mRNA expression of the bone marker ALP (ALPL), relative to that of the housekeeping gene RSP27A. Results represent the mean and standard deviation of duplicate experiments. Both BI-7 $(p<0.05)$ and BTI-7 $(p<0.01)$ are significantly higher than B-7 and BT-7. b mRNA expression of the fat marker adiponectin $(A D I P O Q)$, relative to that of the housekeeping gene RSP27A. Results represent the mean and standard deviation of duplicate experiments. BI-7 is significantly higher than both B-7 and BTI-7 $(p<0.01)$

the 54,675 probes on the chip, 7755 probes appeared differentially expressed at any time point or treatment, compared with the $t=0$ control, based on a $q$ value of $10^{-5}$ and a minimum $\log _{2}$-fold change of 1 . Our primary interest was to identify genes that controlled the TGF $\beta$ induced switch from adipogenic to osteogenic differentiation. In the current experiment, genes downregulated by TGF $\beta$ are potentially involved in adipogenic differentiation and genes upregulated by TGF $\beta$ in osteogenic differentiation. A comparison between the samples BTI and BI resulted in 2911 differentially expressed probes at any time point, of which 1176 probes (735 genes) were differentially expressed at the early time points (days 1 and 2), when cells become committed for lineage specific differentiation. Extending the $\log _{2}$-fold change from 1 to a minimum of 2 resulted in a reduction of the number of differentially expressed genes between BTI and BI to 109, 
of which 25 were established drug targets according to the DrugBank database (www.drugbank.ca). Visual inspection of the time course for expression of these genes identified nine genes which showed the desired dynamics; that is, modulation at early time points and higher expression in BI than in BTI, as presented in Fig. 5.

\section{Analysis of adipogenic differentiation inhibitors}

For the thus identified target genes, as presented in Table 1, we tested whether commercially available inhibitors could block the adipogenic differentiation of hMSCs under conditions similar to those used for the microarray analysis. We first confirmed the established observation that adipogenic differentiation does not occur in the absence of a PPARG agonist, such as rosiglitazone, and therefore an antagonist of this receptor was not further tested. We did, however, also observe that inhibitors of ADAMTS5 and AKR1B10 prevented adipogenic differentiation of hMSCs, while inhibitors of AGTR1, BDKRB2, and KCNK3 were without effect. Earlier studies in the literature have already indicated that inhibitors of metalloproteinases, including Batimastat, have a negative influence on adipogenic differentiation [23], but this is the first report for an inhibitory effect of an aldoketo reductase inhibitor.

Figure 6a shows the effect of Batimastat on adipogenic and osteogenic differentiation of hMSCs under the experimental conditions used for the microarray analysis. TGF $\beta$ and DMSO, as a vehicle for Batimastat, were used as a positive and a negative control. The data show that Batimastat inhibits adipogenic differentiation in a dosedependent manner but, in contrast to TGF $\beta$, this inhibition does not result in a concomitant enhancement of osteogenic differentiation. A similar observation was made for the AKR1B10 inhibitors Sorbinil (not shown) and Zopolrestat. The quantitative analysis presented in Fig. $6 \mathrm{~b}$ shows that Zopolrestat actively inhibits adipogenic differentiation of hMSCs in a dose-dependent manner, although to a lesser extent than Batimastat.

\section{Discussion}

Osteoporosis is a debilitating disease which affects tens of millions of people worldwide. Postmenopausal women are particularly at risk of developing this disease, since reduced estrogen activity enhances the bone-resorbing

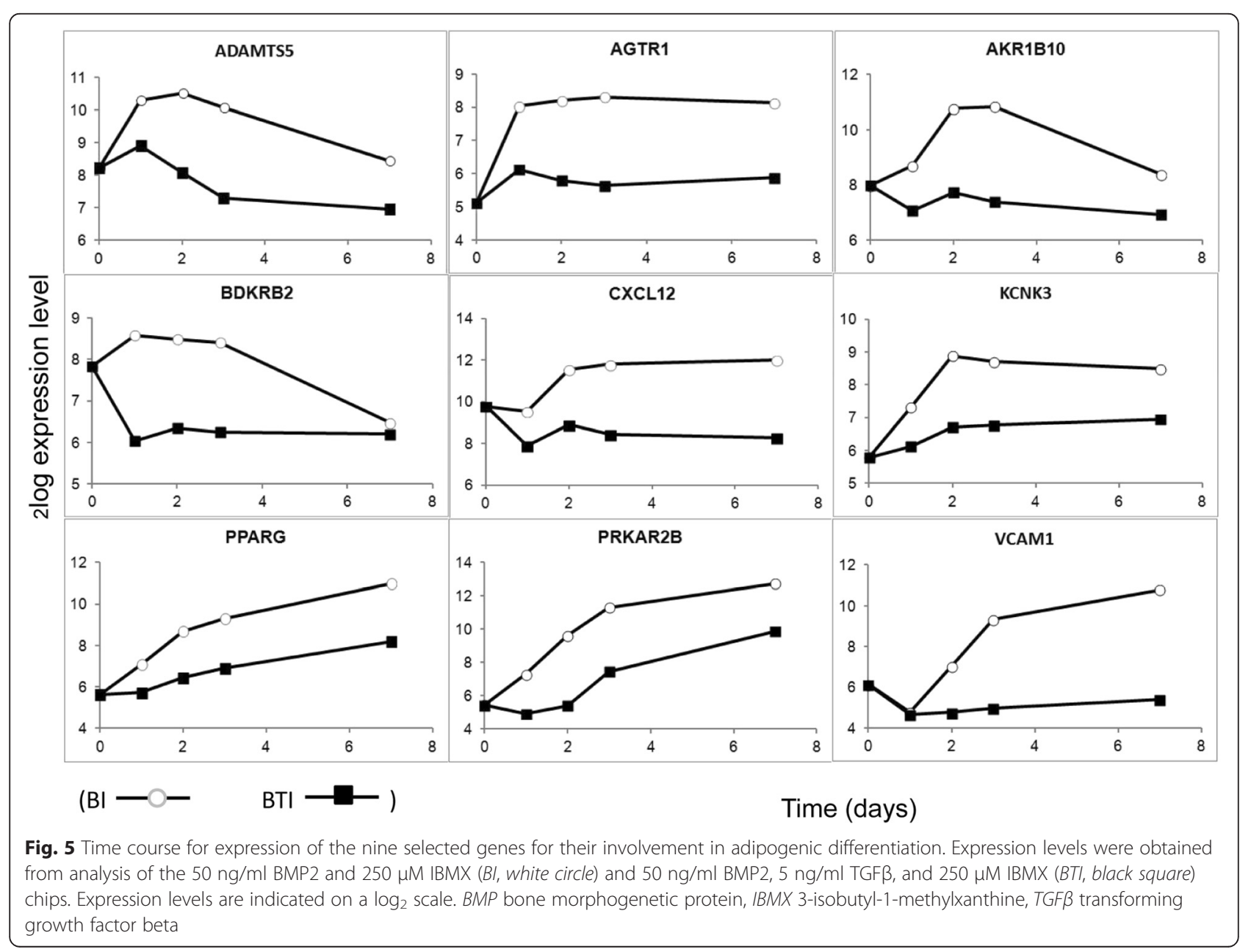


Table 1 Selected genes involved in adipogenic differentiation

\begin{tabular}{llll}
\hline Gene name & Protein function & Inhibitor & Effect \\
\hline ADAMTS5 & Metalloproteinase & Batimastat & Positive \\
AGTR1 & Angiotensin II receptor & Losartan & Negative \\
AKR1B10 & Aldo-keto reductase & Zopolrestat & Positive \\
BDKRB2 & Bradykinin receptor B2 & Icatibant & Negative \\
CXCL12 & Chemokine SDF-1 & (Not tested) & (Not tested) \\
KCNK3 & Potassium channel & Doxapram & Negative \\
PPARG & Nuclear receptor & GW9662 & Positive \\
PRKAR2B & CAMP protein kinase & (Not tested) & (Not tested) \\
VCAM1 & Vascular cell adhesion & (Not tested) & (Not tested) \\
\hline
\end{tabular}

Table presents the HUGO name, function, commercially available drug, and status of experimentally observed effects

positive observed effect, negative no observed effect

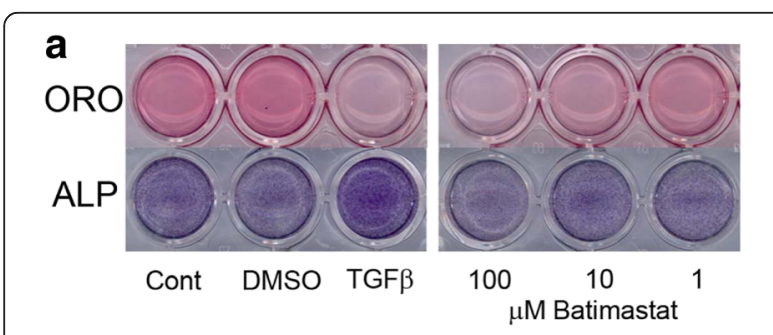

b

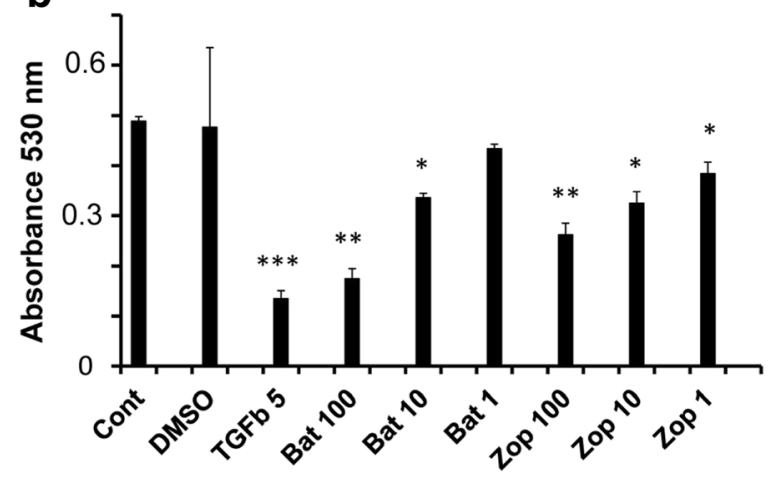

Fig. 6 Effect of selected inhibitors on adipogenic differentiation of hMSCs. a Effect of Batimastat, added at the indicated concentrations to hMSCs in adipogenic differentiation medium, on adipogenic (upper panel; Oil Red O (ORO) staining, day 9) and osteogenic differentiation (lower panel; alkaline phosphatase (ALP) staining, day 7). No addition (Cont), TGF $\beta$ ( $2 \mathrm{ng} / \mathrm{ml})$, and DMSO (0.1\%; used as a solvent for Batimastat) were used as controls. $\mathbf{b}$ Inhibition of adipogenic differentiation by Batimastat (Bat) and Zopolrestat (Zop), added at the indicated micromolar concentrations. Quantitative Oil Red O staining was measured at $530 \mathrm{~nm}$ on hMSCs treated for 9 days with adipogenic differentiation medium. TGF $\beta$ ( $5 \mathrm{ng} / \mathrm{ml}$ ) was used as a control. Significance levels are indicated relative to untreated controls (Cont). ${ }^{*} p<0.05 ;{ }^{* *} p<0.01 ;{ }^{* *} p<0.001$. DMSO dimethyl sulfoxide, TGF $\beta$ transforming growth factor beta activity of osteoclasts. Additionally, aging in general results in a significant reduction in the number and function of bone-forming osteoblasts [24]. Treatment of patients with osteoporosis may include hormone replacement therapies and the use of bisphosphonates to inhibit the activity of osteoclasts. Moreover, vitamin D3 or parathyroid hormone can be prescribed to enhance new bone formation [25]. Recent years have seen an increasing interest in the interaction between fat and bone cells in the bone marrow. Patients suffering from osteoporosis show an increased number of adipocytes in their bone marrow, concomitant with a reduction in the pool of hMSCs that are able to differentiate into osteoblasts $[2,3]$. In addition, adipokines secreted by these adipocytes may further enhance osteoclast activity [26], while an increasing fat content of the bone marrow may also impair the bone cell niche required for the functioning of hematopoietic stem cells [27].

These considerations show that there is great need for developing drugs that prevent the differentiation of hMSCs into fat cells and may thereby enhance their differentiation into bone cells. Likewise, drugs that prevent adipogenic differentiation could also be useful in the battle against obesity. In the present study we have shown that, under proper in-vitro conditions, TGF $\beta$ is able to stimulate osteogenic differentiation and prevent adipogenic differentiation within the same culture. These culture conditions require not only the presence of DEX and BMP, but also of a cAMP-enhancing stimulus such as IBMX or PGE2. Because of its strong side effects TGF $\beta$ is not suited for in-vivo applications, but our results show that the current in-vitro system can be used for identifying genes whose expression is repressed following a TGF $\beta$-induced switch from adipogenic to osteogenic differentiation of hMSCs. By concentrating on those genes for which FDA-approved drugs are available, we have identified nine potential genes that could be tested for inhibition of adipogenic differentiation of hMSCs. Using this approach we have identified the nuclear hormone receptor PPARG, the metalloproteinase ADAMTS5, and the aldo-keto reductase AKR1B10 as potential drug targets for treatment of osteoporosis and obesity.

TGF $\beta$ is a highly pleiotropic cytokine which plays an important role in many physiological processes, as well as in cancer [28, 29]. Because of its strong inhibitory effect on the immune system, systemic treatment with TGF $\beta$ is not considered a realistic option, except for protection against autoimmune diseases [30]. Studies in laboratory animals have shown that TGF $\beta$ treatment can result in skin fibrosis and toxicity, without displaying significant antitumor effects [31, 32]. Local injection of TGF $\beta$ into the knee joint has been shown to enhance cartilage integrity, leading to prevention of osteoarthritis 
[33]. Our present study shows that the effect of TGF $\beta$ on osteogenic differentiation of hMSCs strongly depends on the culture conditions. In osteogenic differentiation medium TGF $\beta$ inhibits bone cell differentiation, while it promotes this process in adipogenic differentiation medium. Since the local conditions in the fatty bone marrow of osteoporosis patients are not well defined, it is difficult to predict whether injection of TGF $\beta$ will result in a net enhancement or a decrease of functional osteoblast cells. Furthermore, current clinical trials directed towards TGF $\beta$ are aimed at inhibiting its activity in cancer patients, since overactivation of TGF $\beta$-induced pathways have been associated with cancer progression $[28,29]$.

Among the genes that were downregulated at early time points following TGF $\beta$ treatment of hMSCs in adipogenic differentiation medium is PPARG. This observation is not unexpected, since ligand-induced activation of PPARG (e.g., by rosiglitazone) is known to be essential for adipogenic differentiation. We have studied the role of PPARG in this process not by using the PPARG-specific antagonist GW9662 (see Table 1), but by omitting rosiglitazone from the culture medium, which resulted in a complete block of fat cell formation (data not shown). The promoting role of PPARG agonists in obesity is well established, but on the contrary these hormones have been shown to be clinically active as antidiabetic drugs [34]. Because of these multiple faces of PPARG, inhibition of this nuclear hormone receptor does not seem an attractive approach for the prevention of fatty bone marrow formation in osteoporosis patients.

The second gene for which inhibitors were found to prevent fat cell differentiation is ADAMTS5, a disintegrin and metalloproteinase with thrombospondin motifs [35]. Its main function is the cleavage of the aggrecan core protein, in which it appears more efficient than other matrix metalloproteinases (MMPs) [36]. Recent studies on Adamts5 $5^{-1-}$ mice, however, have indicated that ADAMTS5 may not responsible for aggrecan proteolysis, but instead regulates glucose uptake by mediating the endocytotic trafficking of LRP1 and GLUT4 [37]. Other studies have shown that deletion of active ADAMTS5 prevents cartilage degradation in a murine model of osteoarthritis [38]. Batimastat and the related drug Marimastat have primarily been developed as antineoplastic drugs. They prevent angiogenesis by blocking metalloproteinases including MMPs and ADAM family members [39]. Both drugs performed poorly in clinical trials on metastatic breast cancer patients [40] and were therefore never marketed. Previous studies have shown that Batimastat blocks the enzymatic activity of MMP2 and MMP9, and prevents the differentiation of mouse 3T3-F442A preadipocytes into fat cells [23, 41]. Our present results show that Batimastat also prevents adipogenic differentiation of hMSCs. Long-term studies on Batimastat and Marimastat in humans are lacking and therefore it cannot be concluded whether these drugs present a real potential for the treatment of patients with osteoporosis or obesity. MMPs are not only involved in cancer progression, but also play an important role in inflammation and immunity [42]. Multiple natural compounds have been identified which seem to block MMP activity [43]. It will be interesting to test the effects of these compounds, some of which are used as food supplements, in relation to osteoporosis and obesity.

In this study we have made the novel observation that inhibitors of aldo-keto reductases prevent adipogenic differentiation of hMSCs. AKR1B10, which was downregulated by TGF $\beta$ in our studies, is particularly active on lipid substrates. It plays an important role in the reduction of retinaldehyde to retinol, as well as in the lipid modification of the K-Ras oncogene. In humans, this gene is particularly expressed in the intestine, adrenal gland, and liver. Inhibition of AKR1B10 prevents the outgrowth of pancreatic carcinoma cells by modulating the Ras pathway [44, 45]. Moreover, expression of AKR1B10 is considered to be a tumor marker for NSCLC [46] and liver tumors [47]. To the best of our knowledge, a role of AKR1B10 in adipogenic differentiation has not yet been studied. However, an RNA-mediated knockdown study has indicated that AKR1B10 is an important regulator of fatty acid biosynthesis in human RAO-3 breast cancer cells [48].

$A K R 1 B 10$ is structurally very similar to $A K R 1 B 1$, and many inhibitors of AKR1B1 also bind AKR1B10. These include the drugs Sorbinil and Zopolrestat, which have been used in the present study. These and related FDAapproved drugs are used particularly for treatment of patients with diabetic polyneuropathy [49]. They do so by inhibiting the metabolism of glucose by the so-called polyol pathway, which converts glucose into sorbitol. This reduced sugar accumulates in the cell and, as a result of osmotic stress, induces microvascular damage to the retina, kidney, and nerves. Although each of these drugs has its specific adverse effects, including rash, toxicity, and hypersensitivity reactions, at least some of them were well tolerated in clinical trials lasting more than a year [49]. However, no long-term beneficial effects of these drugs were observed in diabetes patients. More recently, AKR1B1 inhibitors have also been tested as anticancer drugs [50]. So far, no reports have been made in the literature on the effects of aldo-keto reductase inhibitors on patients with osteoporosis or obesity. Similar to observations for MMPs, multiple naturally occurring inhibitors for aldo-keto reductases have been identified, particularly from plant tissue [51, 52]. Feeding mice with the most potent of these natural AKR1B inhibitors, bisdemethoxycurcumin, has been shown to reduce particularly the incidence of intestinal cancer. Interestingly, some of these natural compounds inhibit 
not only AKR1B members but also MMPs. In ongoing research we are testing the effects of these natural compounds on fat cell differentiation. These studies may provide a lead towards the further development of more optimized compounds which specifically prevent adipogenic differentiation in vivo.

TGF $\beta$ is generally considered to be an inhibitor of bone cell differentiation, but our current results show that in the presence of cAMP-enhancing agents TGF $\beta$ is able to promote osteogenic differentiation. PGE2, which has been shown to raise cAMP levels in hMSCs [53], is known to stimulate osteogenesis upon short-term admission in vivo [54], but it is unclear whether PGE2 exerts its action by preventing TGF $\beta$ from inhibiting bone formation. Kim et al. [12] have shown that cAMP-activated protein kinases play a central role in the choice between osteogenic and adipogenic differentiation of hMSCs, but again no correlation was made with the activity of TGF $\beta$. Our present data are summarized in Fig. 7, which show that PPARG, the nuclear transcription factor essential for adipogenic commitment, is inhibited by TGF $\beta$, which consequently suppresses the maturation to adiponectin and Oil Red Opositive fat cells. On its own TGF $\beta$ suppresses the activity of RUNX2, the nuclear transcription factor essential for osteogenic commitment by a SMAD3/HDAC5-mediated mechanism [20], resulting in impaired maturation to ALP and matrix mineralization-positive bone cells. However, in the presence of IBMX, which strongly represses HDAC5, TGF $\beta$ becomes an activator of RUNX2-mediated osteogenesis. Obviously, the TGF $\beta$-mediated inhibition of adipogenesis is not HDAC5 sensitive.

Using our gene expression microarray analysis we have identified novel inhibitors of adipogenic differentiation. We thereby focused on genes which were differentially expressed on days 1 and 2 following TGF $\beta$ treatment.
This time frame corresponds with the upregulation of commitment genes for adipogenic differentiation such as PPARG, as shown in Fig. 5. Genes differentially expressed at later time points were particularly involved in fatty acid metabolism (data not shown). Figure 6a shows that under the experimental conditions tested inhibitors of these adipogenic commitment genes did not promote osteogenic differentiation to the same extent as TGF $\beta$. The possibility should therefore be considered that within 24-48 hours the cells have already undergone an irreversible commitment towards either adipogenic or osteogenic differentiation. In that respect it may be interesting to study whether TGF $\beta$ added at later time points can still promote cells under adipogenic differentiation conditions to become osteoblasts. Alternatively, the possibility should be considered that under high cAMP conditions TGF $\beta$ is able to stimulate specific pathways leading to osteogenic differentiation. Our current results showing that, in the presence of cAMP-enhancing agents, TGF $\beta$ is able to prevent the formation of fat cells and promote the formation of bone cells have been obtained on commercially available mesenchymal stem cells from bone marrow of healthy human donors. Given the observation that patients suffering from osteoporosis show an increased number of adipocytes in their bone marrow, it will be interesting to carry out similar experiments with mesenchymal stem cells from such patients. This may indicate if this aberrant pattern of differentiation results from intrinsic changes in their stem cells or from an altered microenvironment in their bone marrow.

\section{Conclusions}

Our data show that in the presence of cAMP-enhancing agents TGF $\beta$ stimulates the ability of hMSCs to differentiate into bone cells, while impairing their ability to

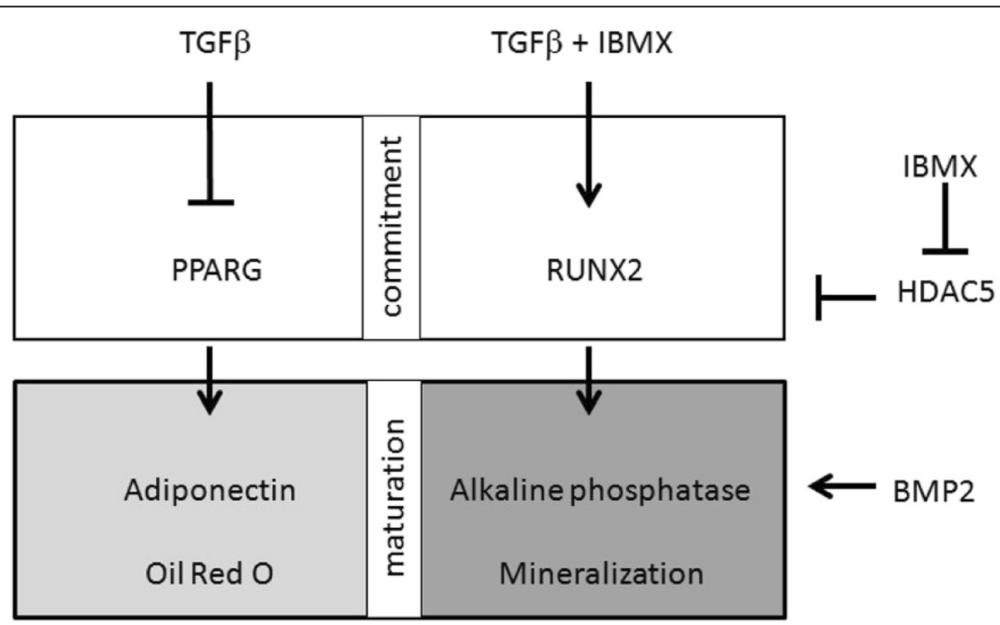

Fig. 7 Overview of signaling pathways activated in hMSCS by TGF $\beta$ in the absence and presence of IBMX: adipogenic differentiation (left) and osteogenic differentiation (right). For details, see text. BMP bone morphogenetic protein, HDAC histone deacetylate, IBMX 3-isobutyl-1-methylxanthine, TGF $\beta$ transforming growth factor beta 
differentiate into fat cells. Under these conditions TGF $\beta$ treatment results in a reduced expression of genes which contribute to adipogenic differentiation, including PPARG, $A D A M T S 5$, and $A K R 1 B 10$. Since FDA-approved drugs are available for these genes, they are potential targets for treatment of patients suffering from osteoporosis or obesity.

\section{Abbreviations}

ADM, adipogenic differentiation medium; ALP, alkaline phosphatase; BMP, bone morphogenetic protein; DAVID, Database for Annotation, Visualization and Integrated Discovery; DEX, dexamethasone; DMEM, Dulbecco's modified Eagle's medium; DMSO, dimethyl sulfoxide; hMSC, human mesenchymal stem cell; IBMX, 3-isobutyl-1-methylxanthine; LIMMA, Linear Models for Microarray Data; MMP, matrix metalloproteinase; ODM, osteogenic differentiation medium; PGE2, prostaglandin E2; PM, proliferation medium; PNPP, $p$-nitrophenyl phosphate; RMA, robust microarray analysis; TGF $\beta$, transforming growth factor beta.

\section{Acknowledgements}

The authors would like to thank Dr Ester Piek and Ingrid de Grijs for their contributions in the initial phase of the project and Dr W. Olijve for fruitful discussions. The present studies were made possible by a grant from ERASysBio + to the LINCONET consortium (Dutch contribution obtained from ZonMw, grant 90201174). Merck Sharpe \& Dohme (Oss, the Netherlands) is acknowledged for financial support in the initial phase of this project. Microarray hybridizations were carried out by the MicroArray Department at the University of Amsterdam.

\section{Authors' contributions}

EJVZ was responsible for the overall design of the study and drafted the final manuscript. ID was responsible for drafting the manuscript with respect to the microarray data and for a critical evaluation of the manuscript. JMH carried out the cell biological assays and was involved in drafting the experimental part of the manuscript. SPvdW was responsible for the design of the cell biological experiments, drafted the cell biological part of the manuscript, and made critical revisions to the final draft. All authors read and approved the final manuscript.

\section{Competing interests}

The authors declare that they have no competing interests.

\section{Author details \\ 'Department of Cell and Applied Biology, Faculty of Science, Radboud University Nijmegen, PO Box 9010, 6500 GL Nijmegen, The Netherlands. 2Present Address: Department of Cell and Applied Biology, Radboud University Nijmegen, Heyendaalseweg 135, 6525 AJ Nijmegen, The Netherlands. ${ }^{3}$ Present Address: Systems Biology and Bioinformatics Laboratory (SysBioLab), University of Algarve, Faro, Portugal. ${ }^{4}$ Present Address: Department of Physical Organic Chemistry, Radboud University Nijmegen, Nijmegen, The Netherlands. ${ }^{5}$ Present Address: ARGENX BVBA Technologiepark 30, B-9052 Zwijnaarde, Belgium.}

Received: 7 January 2016 Revised: 12 July 2016

Accepted: 25 July 2016

Published online: 26 August 2016

\section{References}

1. Pino AM, Rosen CJ, Rodriguez JP. In osteoporosis, differentiation of mesenchymal stem cells (MSCs) improves bone marrow adipogenesis. Biol Res. 2012;45(3):279-87.

2. Justesen J, et al. Adipocyte tissue volume in bone marrow is increased with aging and in patients with osteoporosis. Biogerontology. 2001;2(3):165-71.

3. Rosen CJ, et al. Marrow fat and the bone microenvironment: developmental, functional, and pathological implications. Crit Rev Eukaryot Gene Expr. 2009; 19(2):109-24.

4. Moerman E, et al. Aging activates adipogenic and suppresses osteogenic programs in mesenchymal marrow stroma/stem cells: the role of PPAR-gamma2 transcription factor and TGF-beta/BMP signaling pathways. Aging Cell. 2004;3(6): 379-89.

5. Ito $\mathrm{H}$. Clinical considerations of regenerative medicine in osteoporosis. Curr Osteoporos Rep. 2014;12(2):230-4.

6. Reid IR. Short-term and long-term effects of osteoporosis therapies. Nat Rev Endocrinol. 2015;11(7):418-28.
7. Sotoca AM, Weber M, Zoelen EJJ. Gene expression regulation underlying osteo-, adipo-, and chondro-genic lineage commitment of human mesenchymal stem cells. In: Daskalaki A, editor. Medical Advancements in Aging and Regenerative Technologies: Clinical Tools and Applications. Hershey: IGl Global; 2013. p. 76-94.

8. Muruganandan S, Roman AA, Sinal CJ. Adipocyte differentiation of bone marrow-derived mesenchymal stem cells: cross talk with the osteoblastogenic program. Cell Mol Life Sci. 2009;66(2):236-53.

9. Bennett CN, et al. Regulation of osteoblastogenesis and bone mass by Wnt10b. Proc Natl Acad Sci U S A. 2005;102(9):3324-9.

10. Roelen BA, Dijke P. Controlling mesenchymal stem cell differentiation by TGFBeta family members. J Orthop Sci. 2003;8(5):740-8.

11. Rosen ED, MacDougald OA. Adipocyte differentiation from the inside out Nat Rev Mol Cell Biol. 2006;7(12):885-96.

12. Kim EK, et al. Human mesenchymal stem cell differentiation to the osteogenic or adipogenic lineage is regulated by AMP-activated protein kinase. J Cell Physiol. 2012;227(4):1680-7.

13. Piek E, et al. Osteo-transcriptomics of human mesenchymal stem cells: accelerated gene expression and osteoblast differentiation induced by vitamin D reveals C-MYC as an enhancer of BMP2-induced osteogenesis. Bone. 2010:46(3):613-27.

14. Eijssen $L M$, et al. User-friendly solutions for microarray quality control and pre-processing on ArrayAnalysis.org. Nucleic Acids Res. 2013;41(Web Server issue):W71-6.

15. Irizarry RA, et al. Exploration, normalization, and summaries of high density oligonucleotide array probe level data. Biostatistics. 2003;4(2): 249-64.

16. Smyth GK. Linear models and empirical bayes methods for assessing differential expression in microarray experiments. Stat Appl Genet Mol Biol. 2004:3:Article3.

17. da Huang W, Sherman BT, Lempicki RA. Systematic and integrative analysis of large gene lists using DAVID bioinformatics resources. Nat Protoc. 2009; 4(1):44-57.

18. da Huang W, Sherman BT, Lempicki RA. Bioinformatics enrichment tools: paths toward the comprehensive functional analysis of large gene lists. Nucleic Acids Res. 2009:37(1):1-13.

19. Wishart DS, et al. DrugBank: a comprehensive resource for in silico drug discovery and exploration. Nucleic Acids Res. 2006:34(Database issue):D668-72.

20. Kang JS, et al. Repression of Runx2 function by TGF-beta through recruitment of class II histone deacetylases by Smad3. Embo J. 2005;24(14):2543-55.

21. Maroni $P$, et al. Chemical and genetic blockade of HDACs enhances osteogenic differentiation of human adipose tissue-derived stem cells by oppositely affecting osteogenic and adipogenic transcription factors. Biochem Biophys Res Commun. 2012;428(2):271-7.

22. Zhou Y, Peng J, Jiang S. Role of histone acetyltransferases and histone deacetylases in adipocyte differentiation and adipogenesis. Eur J Cell Biol. 2014:93(4):170-7.

23. Bouloumie A, et al. Adipocyte produces matrix metalloproteinases 2 and 9 : involvement in adipose differentiation. Diabetes. 2001;50(9):2080-6.

24. Bermeo S, Gunaratnam K, Duque G. Fat and bone interactions. Curr Osteoporos Rep. 2014;12(2):235-42

25. Komm BS, et al. The safety and tolerability profile of therapies for the prevention and treatment of osteoporosis in postmenopausal women. Expert Rev Clin Pharmacol. 2015;8(6):769-84.

26. Devlin MJ, Rosen CJ. The bone-fat interface: basic and clinical implications of marrow adiposity. Lancet Diabetes Endocrinol. 2015;3(2):141-7.

27. Tuljapurkar SR, et al. Changes in human bone marrow fat content associated with changes in hematopoietic stem cell numbers and cytokine levels with aging. J Anat. 2011;219(5):574-81.

28. Wrzesinski SH, Wan YY, Flavell RA. Transforming growth factor-beta and the immune response: implications for anticancer therapy. Clin Cancer Res. 2007;13(18 Pt 1):5262-70.

29. Neuzillet $C$, et al. Targeting the TGFbeta pathway for cancer therapy. Pharmacol Ther. 2015;147:22-31.

30. Santambrogio $L$, et al. Studies on the mechanisms by which transforming growth factor-beta (TGF-beta) protects against allergic encephalomyelitis. Antagonism between TGF-beta and tumor necrosis factor. J Immunol. 1993:151(2):1116-27.

31. Mori T, et al. Role and interaction of connective tissue growth factor with transforming growth factor-beta in persistent fibrosis: a mouse fibrosis model. J Cell Physiol. 1999;181(1):153-9. 
32. Robinson SP, Rose WC. Transforming growth factor beta 1: lack of in vivo antitumor activity on A549 and Wehi 3BD+ tumors. Anticancer Res. 1992; 12(1):73-9.

33. Blaney Davidson EN, van der Kraan PM, van den Berg WB. TGF-beta and osteoarthritis. Osteoarthritis Cartilage. 2007;15(6):597-604.

34. Lehrke M, Lazar MA. The many faces of PPARgamma. Cell. 2005;123(6):993-9.

35. Seals DF, Courtneidge SA. The ADAMs family of metalloproteases: multidomain proteins with multiple functions. Genes Dev. 2003;17(1):7-30.

36. Durigova M, et al. MMPs are less efficient than ADAMTS5 in cleaving aggrecan core protein. Matrix Biol. 2011;30(2):145-53.

37. Gorski DJ, et al. Deletion of ADAMTS5 does not affect aggrecan or versican degradation but promotes glucose uptake and proteoglycan synthesis in murine adipose derived stromal cells. Matrix Biol. 2015;47:66-84.

38. Glasson SS, et al. Deletion of active ADAMTS5 prevents cartilage degradation in a murine model of osteoarthritis. Nature. 2005:434(7033):644-8.

39. Rothenberg ML, Nelson AR, Hande KR. New drugs on the horizon: matrix metalloproteinase inhibitors. Stem Cells. 1999;17(4):237-40.

40. Sparano JA, et al. Randomized phase III trial of marimastat versus placebo in patients with metastatic breast cancer who have responding or stable disease after first-line chemotherapy: Eastern Cooperative Oncology Group trial E2196. J Clin Oncol. 2004;22(23):4683-90.

41. Bourlier $V$, et al. Protease inhibitor treatments reveal specific involvement of matrix metalloproteinase-9 in human adipocyte differentiation. J Pharmacol Exp Ther. 2005;312(3):1272-9.

42. Khokha R, Murthy A, Weiss A. Metalloproteinases and their natural inhibitors in inflammation and immunity. Nat Rev Immunol. 2013;13(9):649-65.

43. Mannello F. Natural bio-drugs as matrix metalloproteinase inhibitors: new perspectives on the horizon? Recent Pat Anticancer Drug Discov. 2006; 1(1):91-103.

44. Penning TM. The aldo-keto reductases (AKRs): overview. Chem Biol Interact. 2015;234:236-46.

45. Zhang $W$, et al. Knockdown or inhibition of aldo-keto reductase $1 \mathrm{~B} 10$ inhibits pancreatic carcinoma growth via modulating Kras-E-cadherin pathway. Cancer Lett. 2014;355(2):273-80.

46. Fukumoto $\mathrm{S}$, et al. Overexpression of the aldo-keto reductase family protein AKR1B10 is highly correlated with smokers' non-small cell lung carcinomas. Clin Cancer Res. 2005;11(5):1776-85.

47. Liu Z, et al. Epidermal growth factor induces tumour marker AKR1B10 expression through activator protein-1 signalling in hepatocellular carcinoma cells. Biochem J. 2012;442(2):273-82.

48. Ma J, et al. Aldo-keto reductase family 1 B10 affects fatty acid synthesis by regulating the stability of acetyl-CoA carboxylase-alpha in breast cancer cells. J Biol Chem. 2008;283(6):3418-23.

49. Chalk C, Benstead TJ, Moore F. Aldose reductase inhibitors for the treatment of diabetic polyneuropathy. Cochrane Database Syst Rev. 2007;4:Cd004572

50. Liu J, Wen G, Cao D. Aldo-keto reductase family 1 member B1 inhibitors: old drugs with new perspectives. Recent Pat Anticancer Drug Discov. 2009:4(3):246-53.

51. Matsunaga T, et al. Potent and selective inhibition of the tumor marker AKR1B10 by bisdemethoxycurcumin: probing the active site of the enzyme with molecular modeling and site-directed mutagenesis. Biochem Biophys Res Commun. 2009;389(1):128-32.

52. Endo $\mathrm{S}$, et al. Selective inhibition of the tumor marker AKR1B10 by antiinflammatory $\mathrm{N}$-phenylanthranilic acids and glycyrrhetic acid. Biol Pharm Bull. 2010;33(5):886-90.

53. Kleiveland CR, Kassem M, Lea T. Human mesenchymal stem cell proliferation is regulated by PGE2 through differential activation of cAMP-dependent protein kinase isoforms. Exp Cell Res. 2008;314(8): 1831-8.

54. Tian XY, et al. Continuous PGE2 leads to net bone loss while intermittent PGE2 leads to net bone gain in lumbar vertebral bodies of adult female rats. Bone. 2008;42(5):914-20.

\section{Submit your next manuscript to BioMed Central and we will help you at every step:}

- We accept pre-submission inquiries

- Our selector tool helps you to find the most relevant journal

- We provide round the clock customer support

- Convenient online submission

- Thorough peer review

- Inclusion in PubMed and all major indexing services

- Maximum visibility for your research

Submit your manuscript at www.biomedcentral.com/submit

C Biomed Central 